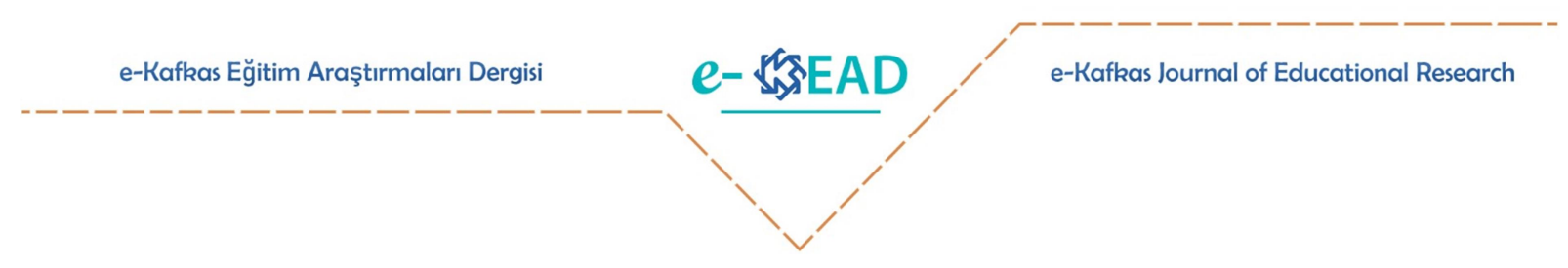

\title{
Erken Çocukluk Dönemindeki Çocuklarla İlgili Bilgi Paylaşımı Yapan Web Sayfalarının İncelenmesi **
}

\section{Investigation of web pages that share information about children in early childhood*

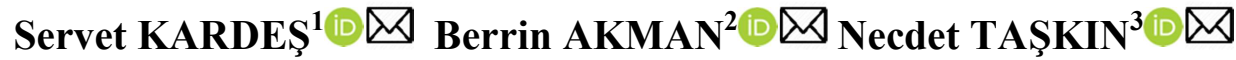

Atıf: Kardeş, S., Akman, B. \& Taşkın, N. (2019). Erken çocukluk dönemindeki çocuklarla ilgili bilgi paylaşımı yapan web sayfalarının incelenmesi. e- Kafkas Eğitim Araştırmaları Dergisi, 6(4), 10-20.

Araştırma Makalesi Geliş Tarihi: 06.11.2019 Kabul Tarihi:28.12.2019

Doi: $10.30900 /$ kafkasegt.643742

\begin{abstract}
$\ddot{O} \mathbf{z}$
Erken çocukluk eğitim alanında bilgi veren web sayfalarının niteliği ve bilgi paylaşımı ile ilgili daha önce araştırma yapılmamış olması bu araştırmanın özgünlüğünü oluşturmaktadır. Çocukluk dönemiyle ilgili bilgi paylaşımı yapan sitelerin incelenmesi ve niteliğinin ortaya konulması araştırmacıların bu alandaki uygulamaları ve eksikleri görmelerine yol açacaktır. Bu araştırmada erken çocukluk dönemindeki çocuklara yönelik bilgi paylaşımı yapan sitelerin içeriğinin incelenmesi amaçlanmıştır. Araştırmada nitel araştırma yöntemlerinden durum çalışması deseni kullanılmıştır. Araştırmada yaygın kullanılan bir arama motoru ile "okul öncesi" "okul öncesi eğitim" ve "erken çocukluk eğitimi" anahtar kelimeleri sonucu listelenen 13 web sitesi, kontrol listesi ile incelenmiş ve site yöneticilerinden yarı yapılandırılmış görüşme formu aracilığıyla veri toplanmıştır. Elde edilen veriler içerik analizi yoluyla analiz edilmiş̧ir. Sonuç olarak web sayfalarında genel olarak bilgi zenginliği olduğu, ticari amaçla kurulan web sayfalarında bilgi güvenilirliğinin yeterli olmadığı, herkese açık erişim sağlandığı, içeriklerin genel olarak yenilikçi olmadığı görülmüştür. Sayfa kullanıcıları için aktif etkileşimin olmadığı elde edilen bir diğer sonuç olmuştur. Site yöneticileri web sayfalarını genelde anne baba ve öğretmenlere yönelik içeriklerle oluşturmaktadır. Site yöneticileri kullanıcıların bilinçlendirilmesi, içeriklerin yayınlanmadan önce uzman kontrolünden geçmesi ve kaynak gösterilerek verilmesi gerektiğini ifade etmişlerdir. Öneri olarak erken çocukluk eğitimi alanında bilgi paylaşımı yapan sitelerin uzman denetiminde kurulması önerilebilir.
\end{abstract}

Anahtar Sözcükler: Erken çocukluk, erken çocukluk eğitimi, internet, web sayfası

\section{Abstract}

The originality of this research is the lack of previous research on the quality of web pages and information sharing. Examination of the web sites that share information about childhood and revealing their quality will lead researchers to see the applications and deficiencies in this field In this research, it is aimed to examine the content of webpages that share information about early childhood. Case study design, one of the qualitative research methods, was used in the study. In this research, 13 websites listed as a result of the keywords "preschool", "preschool education" and "early childhood education" with a common search engine. Data were collected from the checklist and semi-structured interview form from the site administrators. The data obtained were analyzed by content analysis. As a result, there is a wealth of information in the web pages, information reliability is not sufficient in the web pages established for commercial purposes, public access is provided and content is not innovative in general. Another result was that there was no active interaction for page users. Webpage asministrators often create web pages with content for parents and teachers. Site administrators stated that users should be informed, content should be under expert control before publication and should be given with reference. It can be suggested that the sites sharing information in the field of early childhood education should be established under the expert supervision.

Keywords: Early childhood, early childhood education, internet, web pages

\footnotetext{
${ }^{*}$ Bu araştırma 6. Uluslararası Okul Öncesi Eğitimi Kongresinde (IECEC/UOEK-2019) sözlü bildiri olarak sunulmuştur.
} 


\section{Giriş}

İnternet günümüz bilgi toplumunda bilgiye ulaşmak için kullanılan en önemli araçlardan bir tanesidir. 2019 yılı istatistiklerine göre dünya nüfusunun yaklaşık \% 57'si internet kullanıcısı ve dünya nüfusunun \% 45'i sosyal medya kullanıcısıdır (Digital in, 2019). İnternet düşük maliyetlerle ayrıntılı bilgiye ulaşmada, büyük kitlelere erişebilmede ve bireyler arasında etkileşim sağlamada etkili bir iletişim kanalıdır. İnternet ortamında çeşitli amaçlar doğrultusunda hazırlanan ve farklı hedef kitlelere hitap eden web sitelerinin sayısı hızla artmaktadır. Dolayısıyla diğer alanlarda olduğu gibi eğitim alanında da internet sitelerinin sayısı hızla artmıştır. Son yıllarda özellikle internet ortamında erken çocukluk dönemindeki çocukların gelişimi ve eğitimiyle ilgili bilgi paylaşan web sitelerinin sayısı artış göstermektedir. Bu web sayfalarının çoğu ticari amaçlı kurulurken bazı sitelerin vakıflara ya da devlet kurumlarına ait olduğu görülmektedir.

Internet ve medya teknolojileri, akıllı telefonlar ve tabletler erken çocukluk eğitiminde artan bir şekilde kullanılmaya başlanmıştır. Erken çocukluk eğitiminde internet ve teknoloji çok fazla kullanıldığı için sorulması gereken soru; internet ve sosyal medya içerikleri çocukların öğrenmesinde ve gelişiminde nasıl faydalı olabilir? sorusudur. İnternetin ve sosyal medya içeriklerinin erken çocukluk dönemindeki çocukların gelişimi üzerine olan etkileriyle ilgili tartışmalarda ortaya çıkmıştır. Bazı araştırmalarda (Clarke \& Svanaes, 2014; Heafner, 2004; Parette, Quesenberry \& Blum, 2010; Plowman, Stevenson,Stephen \& McPake, 2012) erken çocukluk döneminde sosyal medya içeriklerinin ve internet teknolojisinin faydaları anlatılırken, araştırmaların çoğunda (Clark, 1994; Cornelius \& Boss, 2003; Li, 2006; Lindahl \& Folkesson, 2012; Radesky, Schumacher \& Zuckerman, 2015; Salomon, 1997; Scott \& O’Sullivan, 2000; Tsitouridou \& Vryzas, 2004) medya kullanımının zararları yer almaktadır. Bununla birlikte erken çocuklukta medya kullanımı tam olarak formüle edilmese bile 2 yaşın üzerinde olan çocukların sınırlı ve denetimli medya kullanımlarının kabul edilebileceği ifade edilmektedir (Radesky vd., 2015).

Akıllı telefon ve tabletler gibi interaktif cihazlar ve internet kullanımı çocuklar arasında oldukça yaygındır ve çoğu zaman ebeveynler bu araçları bilinçsiz olarak çocukları için davranış düzenleme aracı olarak kullanabilmektedirler. Bu cihazlar ve internet kullanımı kısa vade de çözüm olsa bile uzun dönemde çocukların sosyal duygusal gelişimi ve iletişim becerileri üzerinde olumsuz etkiler burakabilmektedir (Scott \& O'Sullivan, 2000). Bir diğer tehlike ise internette erken çocukluk dönemindeki çocuklara yönelik hazırlanmış ve hiçbir kanıta dayalı olmadan, gelişimsel ve eğitimsel olarak bu dönemdeki çocuklara uygun ve çocukların kullanımı için güvenli olduklarını iddia eden uygulamalardır. Aileler bu uygulamaların, çocuklarının gelişimine uygun ve eğitici uygulamalar olduğunu düşünerek çocuklarını saatlerce tek başlarına ekran başına bırakabilmektedirler. Bu durum çocukların sağlıklı gelişimi açısından riskler barındırmaktadır. Nitekim öz düzenleme, empati, sosyal beceriler, duygu düzenleme ve problem çözme becerilerinin, çocukların çevrelerini keşfederek, çevrelerindeki yetişkinlerle etkileşime girerek ve yapılandırılmamış oyunlarla kazandıkları yapılan araştırmalarla ortaya çıkmıştır (Radesky vd., 2015). Dolayısıyla kontrolsüz bir şekilde ekran başında vakit geçirmenin çocuklar için gelişimsel sorunlar ve gecikmeler içereceği öngörülebilir.

Teknoloji ve internet doğru kullanıldığında çocukları öğrenme sürecine dahil edebilmektedir. Çocukların gelişimine ve eğitim ihtiyaçlarına uygun düzenlenmiş programlar ve uygulamalar, çocukların bilgilerini arttırabilir ve çocukların ilgilerini canlı tutabilir (Heafner, 2004). Eğitimde teknoloji kullanımı çocukların teknolojiye aşina olmasını da sağlamaktadır (Cassutto, 2000). Çocuklar teknolojinin günlük yaşamdaki rolüne ilişkin bilgi sahibi olmaktadırlar. İnternet teknolojisi; iletişim, iş yaşamı, öğrenme faaliyetleri ve eğlence için yoğun olarak kullanılmaktadır. Çocukların geleneksel sınıflardaki öğrenmelerden ziyade bilgisayar başındaki öğrenmelerde başarma duygusuyla birlikte daha fazla özgüven sahibi oldukları, sabır göstermeyi öğrendikleri ve bağımsızlıklarının da desteklendiği ifade edilmektedir (Plowman vd., 2012). Bununla birlikte teknoloji destekli bir sinıfta çocukların motivasyonlarının daha yüksek olduğu söylenmektedir (Anderson, 2000).

Erken çocukluk döneminde doğru teknoloji kullanımı için öğretmenlerin teknoloji yeterliliklerinin ve bilgilerinin iyi düzeyde olması gerekmektedir (Parette vd., 2010). Bu nedenle ögretmen yetiştirme programlarında teknoloji kullanımının öğretimi ağılık kazanmalıdır. Erken 
çocukluk eğitimi öğretmenleri araştırma temelli eğitim stratejilerini nasıl kullanacaklarını bilmelidirler. Öğretmenler, teknolojik aletlerin bu dönemdeki çocuklar için niçin önemli olduklarını ve nasıl kullanmaları gerektiğini bilmelidir. Öğretmenler, teknolojik aletleri kullanma becerisine sahip olmalı ve sınıftaki eğitim ortamını teknolojik aletlerle desteklemelidirler (Blum, Parette \& Watts, 2009). Ancak yapılan araştırmada öğretmenlerin kaynak yetersizliği, kendilerine olan güvenin düşük olması, teknik problemler, eğitim olanaklarının yetersizliği, yeterli zaman olmaması ve bilgi eksikliği gibi nedenlerden dolayı sınıflarında teknoloji destekli uygulamalarda yetersiz kaldıkları ortaya çıkmıştır (Al-Senaidi, Lin \& Poirot, 2009; Jones, 2004; Karasavvidis, 2009).

Ailenin sosyal medya kullanımı da ebeveyn çocuk etkileşimini olumsuz etkileyebilir. Aileler genelde internet kullanımını kendi işlerini yapmak ve sosyal medya ağlarında etkileşim kurmak için kullanmaktadırlar (Radesky, Kistin, Zuckerman, Nitzberg, Gross, Kaplan-Sanoff \& Silverstein, 2014). $\mathrm{Bu}$ durumda ebeveyn çocuk arasındaki etkileşim azalmakta ve aile çocuk arasında birlikte nitelikli zaman geçirme süresi azalmaktadır.

Ebeveynler ve öğretmenler arasında internet kullanımı ve sosyal medya ağlarının artan bir şekilde kullanılması ve hatta kimi zaman bağımlılık yapması (Bozkurt, Şahin \& Zoroğlu, 2016) çocuğun gelişiminde önemli birer paydaş olan bu yetişkinlerin çocuğun gelişimi ve eğitimi ile ilgili bilgilerin çoğunu internet sitelerinden ve sosyal medya ağlarından elde etmelerine yol açmaktadır. Teknolojinin gelişmesiyle birlikte internetin ve sosyal medya ağlarının yoğun kullanımıyla birlikte bu alanda da bazı önlemler alınmıştır. Örneğin 2006 yılında kamu kurumları internet kılavuzu yayınlanmış ve internet sitelerinin nasıl olması gerektiği ve içeriğinin yapısıyla ilgili bilgi verilmiştir (Devlet Planlama Teşkilatı Müsteşarlığı, 2006). Bununla birlikte kamu kurumları dışında özel sektörde çocuğun gelişimi ve eğitimi ile ilgili bilgi paylaşımı yapan kar amacı güden birçok internet sitesi bulunmaktadır. $\mathrm{Bu}$ sitelerin denetimsiz bir şekilde hiçbir kalite standardına bağlı olmadan kurulması ve insanlığın gelişimsel açıdan önemli ve hassas bir dönemine yani çocukluğa ilişkin bilgiler paylaşmaları beraberinde bazı riskler getirmektedir. Özellikle ebeveynler dijital okuryazar olmadıkları zaman internetten elde ettikleri bilgileri bir süzgeçten geçirmeden, doğru yanlış ayrımı yapmadan bu bilgileri çocuğun eğitim sürecine uyarlayabilmektedirler.

$\mathrm{Bu}$ araştırmada erken çocukluk dönemindeki çocuklara yönelik bilgi paylaşımı yapan sitelerin içeriğinin incelenmesi amaçlanmıştır. Erken çocukluk eğitim alanında bilgi veren web sayfalarının niteliği ve bilgi paylaşımı ile ilgili daha önce araştırma yapılmamış olması bu araştırmanın özgünlügünü oluşturmaktadır. Çocukluk dönemiyle ilgili bilgi paylaşımı yapan sitelerin incelenmesi ve niteliğinin ortaya konulması araştırmacıların bu alandaki uygulamaları ve eksikleri görmelerine yol açacaktır. Bununla birlikte bu araştırmanın politika belirleyiciler içinde bu sitelere yönelik çalışmalar yapmak için bir kaynak niteliğinde olması beklenmektedir.

\section{Yöntem}

\section{Araştırmanın modeli}

$\mathrm{Bu}$ araştırma nitel araştırma yöntemlerinden durum çalışması olarak desenlenmiştir. Durum çalışmaları 'bir ya da birden fazla olayın, ortamın, programın, sosyal grubun ya da diğer birbirine bağlı sistemlerin derinlemesine incelendiği yöntem olarak tanımlanmaktadır' (Büyüköztürk, 2012). Bu araştırmada üzerinde çalışılan durum "okul öncesi eğitim çağıyla ilgili bilgi paylaşımı yapan web sitelerinin incelenmesi” olarak belirlenmiştir.

\section{Çalışma Grubu}

Araştırmanın çalışma grubunu erken çocukluk dönemindeki çocuklara yönelik bilgi paylaşımı yapan 13 web sayfası ve bu sitelerin yöneticileri oluşturmaktadır. Araştırmada betimsel analizi yapılan sitelerin seçimi 2019 yılının Mart ayında yaygın olarak kullanılan bir arama motorunda "okul öncesi", "okul öncesi eğitim" ve "erken çocukluk eğitimi" anahtar kelimelerinin kullanılması sonucu çıkan sitelerin devlet, vakıf veya dernek, kar amacı güden özel site ayrımı yapılmadan, erken çocukluk eğitimi ile ilgili bilgi paylaşımı yapan sitelerden oluşmaktadır. 


\section{Veri Toplama Araçları}

Araştırmada veri toplama yöntemi olarak web sitelerinin yöneticilerine yönelik uzman görüşleri doğrultusunda oluşturulan yarı yapılandırılmış görüşme formu ve sitelerin incelenmesi amacıyla alan yazın taraması ve uzman görüşleri doğrultusunda oluşturulmuş kontrol listesi kullanılmıştır.

\section{Yarı yapılandırılmış görüşme formu}

$\mathrm{Bu}$ form araştırmacılar tarafından web sayfalarının niteliğinin ortaya konulması amacıyla geliştirilmiştir. Yarı yapılandırılmış görüşme formu alan yazın taraması ve uzman görüşleri doğrultusunda hazırlanmıştır. Hazırlanan görüşme formunda yer alan ifadelerin açıklığı ve soruların kapsam geçerliliği 1'i bilgisayar teknolojileri alanında doktora sahibi uzman, 2'si erken çocukluk eğitimi alanında doktora derecesine sahip uzman olmak üzere 3 uzman tarafindan kontrol edilmiştir. Kontrol sonucunda 1 soru amaca yönelik olmadığ gerekçesiyle formdan çıkarılmış ve bir soru da ifade değişikliğine gidilmiştir. Görüşme formu web sayfalarının niteliği ile ilgili 6 sorudan oluşmaktadır. Yarı yapılandırılmış görüşme formundan örnek sorular aşağıdaki gibidir;

1-Sitenizdeki içerikleri erken çocukluk eğitimi konusunda yeterli görüyor musunuz? Paylaştığınız bilgiler yayınlanmadan ne gibi bir süreçten geçiyor? İçeriklerin editöryal denetimi oluyor mu? oluyor?

2-Sitenizde erken çocukluk eğitimi alanında paylaştı̆̆ınız içerikler genellikle hangi konularda

3-Sitenizde ticari ürünlerin tanıtımını yapıp reklam alıyor musunuz? Alıyorsanız genelde ne tür içerikte reklam alıyorsunuz?

\section{Kontrol Listesi}

Web sayfalarının niteliği için oluşturulan kontrol listesi alanyazın taraması ve alandaki uzmanların görüşleri doğrultusunda 16 maddeden oluşmuştur. Web sitesinin içeriği kontrol listesindeki maddeleri karşıllamıyorsa 0 puan, karşılıyorsa 1 puan olarak puanlama yapılmıştır. Kontrol listesinden alınan en düşük puan 0 en yüksek puan ise 16 olmuştur. Kamu kurumları internet klavuzu bir siteden beklentinin İçeriğin doğruluğu, İçeriğin güncelliği, İçeriğin doyuruculuğu, Açıklık, kolay anlaşılabilirlik, Kolay ve yaygın erişilebilirlik olduğunu ifade etmiştir. Brown (2002) web sayfalarının doğruluk, yetkinlik, yansızlık, içeriğin işlevselliği ve güncellik temel özelliklerine sahip olması gerektiğini ifade etmiştir. Furtado vd. (2003); Cox \& Dale (2002) web sitelerinde kullanım kolaylığı olması gerektiğini ifade etmişlerdir. Yukarıda görüldüğü gibi kontrol listesi hazırlanırken kamu internet siteleri için kurulan klavuz, alanyazında konuyla ilgili araştırma yapan uzmanlar ve alan uzmanlarının görüşlerinden yararlanılmıştır. Web sitelerinin incelenmesi için oluşturulan kontrol listesi aşağıda verilmiştir.

Tablo 1. Web Sitelerinin İncelenmesi İçin Kullanılan Kontrol Listesi.

\begin{tabular}{l}
\hline İfadeler \\
\hline Bilgi zenginliği (DPTM, 2006; Hamil ve Gregory, 1997) \\
\hline Bilgi doğruluğu, kalitesi (DPTM, 2006) \\
\hline Herkese açık erişim (DPTM, 2006) \\
\hline Düzenli güncelleme (Brown, 2002; Chung ve Law, 2003) \\
\hline Etkileşim (Tartışma, forum, sohbet odaları) (Chu, 2001; Hamil ve Gregory, 1997) \\
\hline Bilgi güvenilirliği (Kaynak verme vb.) (Brown, 2002) \\
\hline Sayfanın kullanım kolaylığı (Jeong ve Lambert, 2001; Souza vd., 2000) \\
\hline Yönlendirme (Hamil ve Gregory, 1997) \\
\hline İnanılırlık (Cox ve Dale,2002;Scanlon vd., 1998) \\
\hline Yanıt verme (Kaynama ve Black, 2000; Madu ve Madu, 2002) \\
\hline Açılık (Jeong ve Lambert, 2001) \\
\hline Yenilikçilik (Kaynama ve Black, 2000; Li, Tan ve Xie, 2002) \\
\hline Yetkinlik (Cebeci ve Bek, 2006) \\
\hline Grafik (Bevan, 2004; Scanlon vd., 1998) \\
\hline Yoğlantılar (Cox ve Dale, 2002; Jeong ve Lambert, 2001; Scanlon vd., 1998) \\
\hline
\end{tabular}




\section{Verilerin Analizi}

$\mathrm{Bu}$ araştırmada web sitelerinin incelenmesi ve site yöneticileriyle yapılan görüşmelerin analizi için betimsel analiz tekniği kullanılmıştır. Betimsel analiz durum çalışmalarında veri analizi için kullanılan, durumların detaylı bir betimlemesi ve daha sonra da tema veya sorunların analizini kapsar (Creswell, 2009). Araştırmada bulgulara ilişkin ayrıntılı betimlemeler verilmiş ve site yöneticileriyle yapılan görüşmelerden doğrudan alıntılar yapılmıştır. Site yöneticilerinin görüşlerinin alıntılarla sunulmasında "Y.1, Y2. Ve Y.3" kısaltmaları kullanılmıştır. Web sitelerinin incelenmesi için oluşturulan kontrol listesinin siteler için kullanımında güvenilirliği arttırmak için iki alan uzmanı ayrı ayrı 3 web sitesini inceleyerek sonuçları karşılaştırmıştır. Daha sonra ortaya çıkan sonuç tartışılmış ve üzerinde uzlaşmaya varılmıştır.

\section{Bulgular}

\section{Sitelerin incelenmesine ilişkin bulgular}

Araştırmada yer alan 13 web sitesi ayrı ayrı incelenmiş ve web sitelerine ilişkin bulgular aşağıda verilmiştir.

Tablo 2. Web Sayfalarının İncelenmesine İlişkin Sonuçlar.

\begin{tabular}{|c|c|c|c|c|c|c|c|c|c|c|c|c|c|c|}
\hline & \multicolumn{2}{|c|}{ Site 1} & \multicolumn{2}{|c|}{ Site 2} & \multicolumn{2}{|c|}{ Site 3} & \multicolumn{2}{|c|}{ Site 4} & \multicolumn{2}{|c|}{ Site 5} & \multicolumn{2}{|c|}{ Site 6} & \multicolumn{2}{|c|}{ Site 7} \\
\hline & 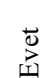 & 胥 & $\sum_{\square=1}^{ \pm}$ & 疍 & $\sum_{\square}^{\vec{D}}$ & 寻 & $\sum_{\square}^{ \pm}$ & 胥 & एٕ & 䔍 & $\stackrel{\vec{\Delta}}{\vec{D}}$ & 奈 & 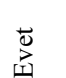 & $\underset{\mathrm{I}}{\overrightarrow{\mathrm{J}}}$ \\
\hline Bilgi zenginliği & $\mathrm{X}$ & & $\mathrm{X}$ & & $\mathrm{X}$ & & $\mathrm{X}$ & & $\mathrm{X}$ & & $\mathrm{X}$ & & $\bar{X}$ & \\
\hline Bilgi doğruluğu, kalitesi & $\mathrm{X}$ & & $\mathrm{X}$ & & $\mathrm{X}$ & & $\mathrm{X}$ & & $\mathrm{X}$ & & $\mathrm{X}$ & & $\mathrm{X}$ & \\
\hline Herkese açık erişim & $\mathrm{X}$ & & $\mathrm{X}$ & & $\mathrm{X}$ & & $\mathrm{X}$ & & & $\mathrm{X}$ & $\mathrm{X}$ & & $\mathrm{X}$ & \\
\hline Düzenli güncelleme & $\mathrm{X}$ & & $\mathrm{X}$ & & $\mathrm{X}$ & & $\mathrm{X}$ & & $\mathrm{X}$ & & $\mathrm{X}$ & & $\mathrm{X}$ & \\
\hline Etkileșim (Tartışma, forum, sohbet odaları) & & $\mathrm{X}$ & & $\mathrm{X}$ & $\mathrm{X}$ & & & $\mathrm{X}$ & & $\mathrm{X}$ & & $\mathrm{X}$ & & $\mathrm{X}$ \\
\hline Bilgi güvenilirliği (Kaynak gösterme vb) & $\mathrm{X}$ & & $\mathrm{X}$ & & $\mathrm{X}$ & & $\mathrm{X}$ & & $\mathrm{X}$ & & $\mathrm{X}$ & & $\mathrm{X}$ & \\
\hline Sayfanın Kullanım kolaylığ 1 & $\mathrm{X}$ & & $\mathrm{X}$ & & $\mathrm{X}$ & & $\mathrm{X}$ & & $\mathrm{X}$ & & $\mathrm{X}$ & & $\mathrm{X}$ & \\
\hline Yönlendirme & $\mathrm{X}$ & & & $\mathrm{X}$ & $\mathrm{X}$ & & & $\mathrm{X}$ & & $\mathrm{X}$ & & $\mathrm{X}$ & & $\mathrm{X}$ \\
\hline İnanılırlık & $\mathrm{X}$ & & $\mathrm{X}$ & & $\mathrm{X}$ & & $\mathrm{X}$ & & $\mathrm{X}$ & & $\mathrm{X}$ & & $\mathrm{X}$ & \\
\hline Yanit verme & & $\mathrm{X}$ & $\mathrm{X}$ & & & $\mathrm{X}$ & & $\mathrm{X}$ & & $\mathrm{X}$ & $\mathrm{X}$ & & & $\mathrm{X}$ \\
\hline Açıklık & $\mathrm{X}$ & & $\mathrm{X}$ & & $\mathrm{X}$ & & $\mathrm{X}$ & & $\mathrm{X}$ & & $\mathrm{X}$ & & $\mathrm{X}$ & \\
\hline Yenilikçilik & & $\mathrm{X}$ & & $\mathrm{X}$ & $\mathrm{X}$ & & $\mathrm{X}$ & & & $\mathrm{X}$ & $\mathrm{X}$ & & & $\mathrm{X}$ \\
\hline Yetkinlik & $\mathrm{X}$ & & $\mathrm{X}$ & & $\mathrm{X}$ & & $\mathrm{X}$ & & $\mathrm{X}$ & & $\mathrm{X}$ & & $\mathrm{X}$ & \\
\hline Grafik & & $\mathrm{X}$ & $\mathrm{X}$ & & $\mathrm{X}$ & & $\mathrm{X}$ & & $\mathrm{X}$ & & $\mathrm{X}$ & & $\mathrm{X}$ & \\
\hline Bağlantılar & $\mathrm{X}$ & & & $\mathrm{X}$ & $\mathrm{X}$ & & & $\mathrm{X}$ & & $\mathrm{X}$ & & $\mathrm{X}$ & $\mathrm{X}$ & \\
\hline Yorumlar & & $\mathrm{X}$ & & $\mathrm{X}$ & & $\mathrm{X}$ & & $\mathrm{X}$ & & $\mathrm{X}$ & & $\mathrm{X}$ & & $\bar{X}$ \\
\hline Toplam & 11 & & 11 & & 14 & & 11 & & 9 & & 12 & & 11 & \\
\hline
\end{tabular}

Tablo 2'de görüldüğü gibi sitelerin genellikle etkileşim, yönlendirme, yanıt verme ve yenilikçilik açısından yetersiz olduğu görülmektedir. Sitelerin bilgi doğruluğu, bilgi kalitesi, düzenli güncelleme, içeriğin çocuk gelişimiyle ilgili olması açısından yeterli olduğu görülmektedir.

Tablo 3. Web Sayfalarının İncelenmesine İlişkin Tablonun Devamı.

\begin{tabular}{|c|c|c|c|c|c|c|c|c|c|c|c|c|}
\hline & \multicolumn{2}{|c|}{ Site 8} & \multicolumn{2}{|c|}{ Site 9} & \multicolumn{2}{|l|}{ Site 10} & \multicolumn{2}{|c|}{ Site 11} & \multicolumn{2}{|c|}{ Site 12} & \multicolumn{2}{|c|}{ Site 13} \\
\hline & $\underset{⿱ 亠 凶}{\vec{\Delta}}$ & $\underset{\Xi}{\stackrel{\Xi}{I}}$ & $\begin{array}{r}\overrightarrow{0} \\
\text { 章 }\end{array}$ & $\underset{\Xi}{\Xi}$ & $\begin{array}{l}\overrightarrow{0} \\
\overrightarrow{1}\end{array}$ & $\underset{\Xi}{\Xi}$ & 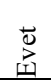 & 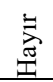 & 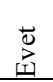 & $\stackrel{\Xi}{\Xi}$ & 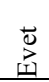 & $\underset{\bar{I}}{\tilde{I}}$ \\
\hline Bilgi zenginliği & $\mathrm{X}$ & & & $\mathrm{X}$ & $\mathrm{X}$ & & & $\mathrm{X}$ & $\mathrm{X}$ & & $\mathrm{X}$ & \\
\hline Bilgi doğruluğu, kalitesi & $\mathrm{X}$ & & $\mathrm{X}$ & & & $\mathrm{X}$ & & $\mathrm{X}$ & $\mathrm{X}$ & & $\mathrm{X}$ & \\
\hline Herkese açık erişim & $\mathrm{X}$ & & & $\mathrm{X}$ & $\mathrm{X}$ & & $\mathrm{X}$ & & $\mathrm{X}$ & & $\mathrm{X}$ & \\
\hline Düzenli güncelleme & $\mathrm{X}$ & & $\mathrm{X}$ & & $\mathrm{X}$ & & & $\mathrm{X}$ & $\mathrm{X}$ & & $\mathrm{X}$ & \\
\hline Etkileşim (Tartışma, forum, sohbet odaları) & & $\mathrm{X}$ & & $\mathrm{X}$ & & $\mathrm{X}$ & & $\mathrm{X}$ & & $\mathrm{X}$ & & $\mathrm{X}$ \\
\hline Bilgi güvenilirliği (Kaynak gösterme vb) & & $\mathrm{X}$ & & $\mathrm{X}$ & & $\mathrm{X}$ & & $\mathrm{X}$ & $\mathrm{X}$ & & $\mathrm{X}$ & \\
\hline Sayfanın Kullanım kolaylığı & $\mathrm{X}$ & & $\mathrm{X}$ & & $\mathrm{X}$ & & $\mathrm{X}$ & & $\mathrm{X}$ & & $\mathrm{X}$ & \\
\hline Yönlendirme & & $\mathrm{X}$ & & $\mathrm{X}$ & & $\mathrm{X}$ & & $\mathrm{X}$ & & $\mathrm{X}$ & & $\mathrm{X}$ \\
\hline İnanılırlık & $\mathrm{X}$ & & $\mathrm{X}$ & & & $\mathrm{X}$ & & $\mathrm{X}$ & $\mathrm{X}$ & & $\mathrm{X}$ & \\
\hline Yanit verme & & $\mathrm{X}$ & & $\mathrm{X}$ & & $\mathrm{X}$ & & $\mathrm{X}$ & $\mathrm{X}$ & & $\mathrm{X}$ & \\
\hline Açıklık & $\mathrm{X}$ & & $\mathrm{X}$ & & $\mathrm{X}$ & & & $\mathrm{X}$ & $\mathrm{X}$ & & $\mathrm{X}$ & \\
\hline Yenilikçilik & & $\mathrm{X}$ & & $\mathrm{X}$ & & $\mathrm{X}$ & & $\mathrm{X}$ & & $\mathrm{X}$ & $\mathrm{X}$ & \\
\hline Yetkinlik & $\mathrm{X}$ & & $X$ & & $\mathrm{X}$ & & $\mathrm{X}$ & & $X$ & & $X$ & \\
\hline Grafik & & $\mathrm{X}$ & & $\mathrm{X}$ & & $\mathrm{X}$ & & $\mathrm{X}$ & $\mathrm{X}$ & & $\mathrm{X}$ & \\
\hline Bağlantılar & & $X$ & & $X$ & & $\mathrm{X}$ & & $\mathrm{X}$ & & $\mathrm{X}$ & & $\mathrm{X}$ \\
\hline Yorumlar & & $\mathrm{X}$ & & $X$ & & $\mathrm{X}$ & & $X$ & & $X$ & & $\mathrm{X}$ \\
\hline Toplam & 8 & & 6 & & 6 & & 3 & & 11 & & 12 & \\
\hline
\end{tabular}


Tablo 3’te görüldüğ̈̈ gibi sitelerin etkileşim, yönlendirme, yenilikçilik, bağlantı ve yorum açısından yetersiz olduğu görülmektedir. Yine sitelerin kullanım kolaylığı, grafik tasarımı, bilgi güvenliği ve herkese açık erişim anlamında işlevsel olduğu görülmektedir.

Araştırma kapsamında görüşme yapılan site yöneticilerinin görüşleri ise aşağıda verilmiştir.

S.3. Sitenizdeki içerikleri erken çocukluk eğitimi konusunda yeterli görüyor musunuz? Paylaştığınız bilgiler yayınlanmadan ne gibi bir süreçten geçiyor? İçeriklerin editöryal denetimi oluyor mu?

Y.1. «itemizdeki içerikler sadece uzmanlar tarafindan yazılmaktadır. Sahibi uzman olmayan herhangi bir yazıya yer vermiyoruz. Güvenilir uzman içeriği bizim vazgeçmeyeceğimiz bir konu. Tüm içeriklerimiz yayınlanmadan önce kontrolden geçmektedir.»

S.4. Sitenizde erken çocukluk eğitimi alanında paylaştığınız içerikler genellikle hangi konularda oluyor?

"Annelik-babalık, Bebek gelişim, Bebek beslenmesi, Çocuk Eğitimi, Çocuk Gelişimi, Gelişim Sorunlar, Konuşma Gelişimi, Sağllk, Uyku Eğitimi, Tuvalet Eğitimi, Hamilelik”"

S.5. Sitenizde ticari ürünlerin tanıtımını yapıp reklam alıyor musunuz? Alıyorsanız genelde ne tür içerikte reklam alıyorsunuz? veriyoruz»

Y.1. «Reklam allyoruz. Sadece güvenilir markalardan çocukların kullanabileceği ürünlere yer

Yukarıdaki site yöneticisinin görüşlerine bakıldığı zaman, sitenin alanında uzman bireylerin görüşlerine önem verdiği ve kaynağı belirsiz olan bilgileri paylaşmadığı görülmektedir. Anne baba, çocuğun gelişimi ve gelişimle ilgili bilgiler sitenin paylaştığı bilgiler arasındadır. Sitenin reklam alanında da güvenli bir yol izlediği görülmektedir.

6. Son olarak erken çocukluk eğitimi alanında faaliyet gösteren web sitelerinin denetimi ve geliştirilmesi için neler yapılabilir?

Y.2. "Bu içeriğe sahip web sitelerinin denetlenmesinden öte öncelikle kullanıcıların bilinçlendirilmesi önem arz etmektedir. Bununla birlikte site sahiplerinin metin içeriklerinin uzman kişiler tarafindan onaylatmış olması, Kaynak gösterebildiği bilgi ve içerikleri paylaşması, Güncel ihtiyaçlara yönelik içerik hazırlanması gibi unsurlar önerilebilir."

Site yöneticisiyle yapılan görüşmede içeriklerin uzmanlar tarafindan belirlenmesinin ve özellikle kullanıcıların site kullanımı hakkında bilinçlendirilmesi gerektiği ifade edilmiştir. Yine paylaşılan bilgilerin güvenilir kaynaklardan elde edilmesi gerektiği üzerinde durulmuştur.

S.4. Sitenizde erken çocukluk eğitimi alanında paylaştı̆̆ınız içerikler genellikle hangi konularda oluyor?

Y.3. «Amacımız çocuk eğitimi konusunda aileleri bilgilendirmek olduğundan çocuk eğitimi ve davranış düzenleme konuları ağırlıklı»

S.6. Son olarak erken çocukluk eğitimi alanında faaliyet gösteren web sitelerinin denetimi ve geliştirilmesi için neler yapılabilir? bildirilmiştir.

Y.3. «Bu amaçla kurulmuş olan bir uzman ekibinin denetimi yararlı olabilir» şeklinde görüşler

\section{Tartışma, Sonuç ve Öneriler}

Araştırmamızda devlet ve vakıflar tarafından kurulan sitelerin güvenilir olduğu ancak ticari amaçla kurulan web sitelerinin bilgi güvenilirliğinin yeterli olmadığı sonucu ortaya çıkmıştır. Ticari amaçla kurulan web siteleri eğitim amaçlı kurulmuş sitelerdir. Dolayısıyla web sitelerinin işlevsel ve verimli olması için, oluşturulan içeriğin kalitesi, tasarım kalitesi, organizasyon kalitesi ve kullanıcı dostu olmaları kriterlerinin göz önüne alınması gerekir. Kurbanoğlu (2009) doğruluk ve güvenilirliğin sitelerin değerlendirilmesinde önemli kriterler olduğunu ifade etmiştir. Dolayısıyla erken çocukluk dönemiyle ilgili bilgi paylaşımı yapan sitelerden de doğru ve güvenilir bilgi paylaşmaları 
beklenmektedir. Esgin, Baba, Aytaç ve Turan (2011) yaptıkları araştırmada katılımcıların internetteki kaynakların doğruluğu ve güvenilirliği hakkında farkındalıklarının yetersiz olduğu sonucuna ulaşmışlardır. Bu durum bireylerin sağlıklı ve doğru bilgiye ulaşımı ve bunu aktarımı konusunda riskler barındırmaktadır. Kılıç Çakmak, Güneş, Çiftçi ve Üstündağ (2011)'da yaptıkları araştırmada tasarlanan web sitelerinin kullanıcılarını memnun etmesi için bu sitelerin etkili, verimli ve işlevsel olması gerektiğini ifade etmişlerdir. Sitelerin önemli bir sorunu da kullanışlılık başlı̆̆ 1 altında güncelleme ve etkileşimin fazla olmamasıdır. Benzer olarak Çelik (2014) yaptığı araştırma sonucunda güncelleme konusunda sitelerin özenli davranmadığı ve kullanıcılara bu konuda bilgi vermediği görülmüştür. Site üyeliği, yorum mekanizması gibi etkileşim gerektiren bölümlerde önemli teknik problemler ile karşılaşılmıştır. Cebeci ve Bek (2006) yaptıkları araştırmada internet sitelerinin kalitesi için doğruluk, yetkinlik ve güncelliğin önemli değerlendirme kriterleri olduğunu belirtmişlerdir. Dolayısıyla internet siteleri, güvenilir kaynaklardan elde ettikleri bilgilerle alandaki gelişmeleri yakından takip etmeli ve alanla ilgili güncellenen bilgileri, yenilikleri ve çocuk gelişimiyle ilgili paylaşılan en son istatistikleri kaynak vererek okuyucularıyla paylaşmalıdır.

Sonuç olarak web sayfalarında genel olarak bilgi zenginliği olduğu, ticari amaçla kurulan web sayfalarında bilgi güvenilirliğinin yeterli olmadığı, ticari amaçla kurulan siteler hariç herkese açık erişim sağlandığı, içeriklerin genel olarak yenilikçi olmadığı ve bilgi güncellemeye önem verilmediği görülmüştür. Sayfa kullanıcıları için aktif etkileşimin olmadığı elde edilen bir diğer sonuç olmuştur. Site yöneticileri web sayfalarını genelde anne baba ve öğretmenlere yönelik içeriklerle oluşturmaktadır. Site yöneticileri kullanıcıların bilinçlendirilmesi, içeriklerin yayınlanmadan önce uzman kontrolünden geçmesi ve kaynak gösterilerek verilmesi gerektiğini ifade etmişlerdir. Kuzu (2011) yaptığı araştırmada hem ebeveynlerin hem çocukların gerek fizyolojik ve gerekse psikososyal sorunlar açısından bilgi ve önlem alma düzeylerinin çok yetersiz olduğunu ortaya koymuştur. Dolayısıyla site içeriklerinin uzman kontrolünden geçmesi bilgi güvenilirliği açısından önemli olacaktır.

Öneri olarak okul öncesi eğitim alanında bilgi paylaşımı yapan sitelerin uzman denetiminde kurulması, ailelere digital okuryazarlık eğitimlerinin verilmesi ve özellikle ticari amaçla kurulan sitelerin kullanılabilirliklerinin arttırılması önerilebilir.

\section{Kaynakça}

Al-Senaidi, S., Lin, L. \& Poirot, J. (2009). Barriers to adopting technology for teaching and learning in Oman. Computers \& Education, 53(3), 575-590

Anderson, M. A. (2000). It's in the research. Library Talk, 13(1), 31-33.

Bevan, N. (2004). Usability Issues in Web Site Design. $<$ http://www.serco.co.uk/Images/Web\%20Paper_tcm3-2251.pdf> adresinden alınmıştır.

Blum, C., Parette, H. P. \& Watts, E. H. (2009). Engaging young children in an emergent literacy curriculum using of Microsoft $\left(\odot\right.$ PowerPoint ${ }^{\mathrm{TM}}$ : Development, considerations and opportunities. Research, reflections and innovations in integrating ICT in education, 1, 41-45.

Bozkurt, H., Şahin, S.\& Zoroğlu, S. (2016). İnternet bağımlılığı: Güncel bir gözden geçirme. Journal Of Contemporary Medicine, 6(3), 235-247.

Brown, J. R. (2002). An evaluation of Missouri High School Library web pages. unpublished master's thesis, Central Missouri State University, Missouri.

Büyüköztürk, Ş., Çakmak, EK., Akgün, KŞ. \& Karadeniz, Ş. (2012) Bilimsel araşttrma yöntemleri Ankara: Pegem Akademi Yayıncilı.

Cassutto, G. (2000). Social studies and the World Wide Web. International Journal of Social Education, 15(1), 94-101.

Cebeci, Z.\& Bek, Y. (2006). İnternet bilgi kaynaklarının kalitesi: Değerlendirme ölçütleri.http://www.cu.edu.tr/fakulteler/zf/zb/bgabd/documents/zcebeci/tik4/intbilkalite.htm adresinden alınmıştır.

Chu, R. (2001). What online hong kong travelers look for on airline / travel websites? Hospitality Management, 20, 95-100.

Chung T. \& Law, R. (2003). Developing a performance indicator for hotel websites. Hospitality Management, 22 (1), 119-125.

Clark, R. E. (1994). Media will never influence learning. Educational Technology, Research and Development, 42(2), 21-29. 
Clarke, B. \& Svanaes, S. (2014). An updated literature review on the use of tablets in education. Tablets for Schools. UK: Family Kids \& Youth.

Cornelius, C. \& Boss, M. (2003). Communication abstracts. Communication and Information Technology, 25(4), 533-555.

Cox, J. \& Dale, B.G. (2002). Key quality factors in web site design and use, an examination. InternationalJournal of Quality \& Reliability Management, 19 (7), 862-888.

Creswell, JW. (2009). Research Design Qualitative, Quantitative, and Mixed Methods Approaches SAGE Publications, Inc

Çelik, T., (2014). Web Sitelerinin Erişilebilirlik Değerlendirmesi Ege Üniversitesi Örneği.The Journal of Academic Social Science Studies, 28, 429-443.

Devlet Planlama Teşkilatı Müsteşarlığı-Bilgi Toplumu Dairesi (2006). Kamu kurumları internet sitesi k1lavuzu.http://www.bilgitoplumu.gov.tr/wpcontent/uploads/2014/04/Kamu_Kurumlari_Intern et Sitesi Kilavuzu.pdfadresinden alınmıștır.

Digital in, (2019). Dünyada internet kullanımı ve sosyal medya istatistikleri.https://dijilopedi.com/2019-internet-kullanimi-ve-sosyal-medya-istatistikleri/ adresinden alınmıştır.

Esgin, E., Baba, Z., Aytaç, N.\& Turan, E. (2011, September). İnternet tabanlı kaynakların doğruluğu ve güvenilirliği hakkındaki farkındalığın incelenmesi. In 5th International computer \& instructional technologies symposium (pp. 22-24), Elazığ, Turkey.

Furtado, E. \& et. al. (2003). Improving usability of an online learning system by means of multimedia, collaboration, and adaptation resources. In Usability evaluation of online learning programs. ed. Claude Ghaoui. 69-86. Hershey. Pa.: Information Science Publication.

Hamil, J. \& Gregory, K. (1997). Internet marketing in the internationalisation of UK SMEs. Journal of Marketing Management, 13, 9-28.

Heafner, T. (2004). Using technology to motivate students to learn social studies. Contemporary Issues in Technology and Teacher Education, 4(1), 42-53.

Jeong, M., Lambert, C., (2001). Adaptation of an information quality framework to measure customers'behavioral intentions to use lodging Web sites. International Journal of Hospitality Management 20(2), 129-146.

Jeong, M., Oh. H. \& Gregoire, M. (2003). Conceptualizing web site quality and its consequences in the lodging industry.Hospitality Management, 22,161-175.

Jones, A. (2004). A review of the research literature on barriers to the uptake of ICT by teachers. Coventry: British Educational Communications and Technology Agency.

Karasavvidis, I. (2009). Activity theory as a conceptual framework for understanding teacher approaches to information and communication technologies. Computers \& Education, 53(2), 436-444.

Kaynama, S.A.\& Black, C.I. (2000). A proposal to assse the service quality of online travel agencies: An exploratory study.Journal of Protessional Services Marketing, 21(1), 63-89.

Kılıç Çakmak, E., Güneş, E., Çiftçi, S., \& Üstündăg, M. T. (2011). Web sitesi kullanılabilirlik ölçeğinin geliştirilmesi: Geçerlik, güvenirlik analizi ve uygulama sonuçları. Pegem Ĕ̈itim ve Öğretim Dergisi, 1(2), 31-40.

Kurbanoğlu, S. (2009). WWW Bilgi kaynaklarının değerlendirilmesi. Hacettepe Üniversiteli Edebiyat Dergisi, 19(1), 11-25.

Kuzu, A. (2011). İnternet ve aile. Aile ve Toplum Eğitim-Kültür ve Araştırma Dergisi, 7(27), 09-32.

Li, Y. N., Tan, K. \& Xie, M. (2002). Measuring Web-based service quality. Total Quality Management \& Business Excellence. 13.685-700.

Li, H. (2006).Integrating information and communication technologies into the early childhood curriculum: Chinese principals' views of the challenges and opportunities. Early Education and Development, 17(3), 467-487.

Lindahl, M.G.\& Folkesson, A.M. (2012). Can we let computers change practice? Educators' interpretations of preschool tradition. Computers in Human Behavior, 28(5), 1728-1737.

Madu, C.N. \& Madu, A.A. (2002). Dimensions of e-quality. InternationalJournal of Quality $\quad \&$ Reliability Management, 19 (3), 246-258.

Parette, H. P., Quesenberry, A. C.\& Blum, C. (2010). Missing the boat with technology usage in 
early childhood settings: A 21st century view of developmentally appropriate practice. Early Childhood Education Journal, 37(5), 335-343.

Plowman, L., Stevenson, O., Stephen, C.\& McPake, J. (2012). Preschool children's learning with technology at home. Computers \& Education, 59(1), 30-37.

Radesky, J. S., Schumacher, J.\& Zuckerman, B. (2015). Mobile and interactive media use by young children: The good, the bad, and the unknown. Pediatrics, 135(1), 1-3.

Radesky, J. S., Kistin, C. J., Zuckerman, B., Nitzberg, K., Gross, J., Kaplan-Sanoff, M., ...\& Silverstein, M. (2014). Patterns of mobile device use by caregivers and children during meals in fast food restaurants. Pediatrics, 133(4), 843-849.

Salomon, G. (1997). Of mind and media. Phi Delta Kappan, 78(5), 375-381.

Scanlon, T., Schroeder, W., Snyder, C. \& Spool, J. (1998). Websites That Work: Designing With Your Eyes Open. Proceedings of The SIGCHI on Human Factors of Computing Systems, Los Angels CA: The Association of Computing Machinery.

Scott, T. J.\& O'Sullivan, M. (2000). The internet and information literacy: Taking the first step toward technology education in the social studies. The Social Studies, 91(3), 121-125.

Souza, R., Manning, H., Goldman, H. \& Tong, J. (2000). The best of retail site design. Forresterresearch:

Techstrategy.http://www.forrester.com/ER/Research/Report/Summary/O,1338,10003,FF.html. adresinden alınmıştır.

Tsitouridou, M. \&Vryzas, K. (2004). The prospect of integrating ICT into the education of young children: The views of Greek early childhood teachers.European Journal of Teacher Education, 27(1), 29-45. 